\title{
O DESAFIO DE PUBLICAR EM PORTUGUÊS
}

Felismina Mendes ${ }^{1}$

RESUMO: Nesta era globalizada e tão fértil em fluxos de informação, somos quotidianamente confrontados com rankings baseados em indicadores bibliométricos, que medem a produção científica de cada investigador. Assiste-se igualmente a uma corrida desenfreada pela publicação e pelos pontos que ela rende, nomeadamente quando se publica em revistas de topo, necessariamente em inglês. A vitória obtida pela publicação nestas revistas parece representar um luxo a que poucos têm acesso. Neste artigo apresenta-se uma reflexão sobre as dinâmicas que definem e controlam os contextos da publicação e as definições da ciência, cuja publicação em português tende a ser relegada para um plano secundário ou marginal.

PALAVRAS-CHAVE: Editoração; Comunicação; Informação.

\section{THE CHALLENGE OF PUBLISHING IN PORTUGUESE}

ABSTRACT: In this globalized era, so rich in the flow of information, one is confronted daily with rankings based on bibliometric indicators, which measure each investigator's scientific production. Equally one sees a reckless race for publication and the points that ensue, specifically when one is published in a top-ranking magazine - necessarily in English. The victory to be obtained by publishing in these magazines seems to represent a luxury to which few have access. This article presents a reflection on the dynamics which define and control the contexts of publication and the definitions of the knowledge, whose publication in Portuguese tends to be relegated to a secondary or marginal plane.

KEYWORDS: Publishing; Communication; Information.

\section{EL DESAFÍO DE PUBLICAR EN PORTUGUÉS}

RESUMEN: En esta era globalizada y tan fértil en cantidad de información, todos los días nos quedamos delante de rankings basados en indicadores bibliométricos, que miden la producción científica de cada investigador. Se asiste igualmente a una verdadera carrera por la publicación y por los puntos que ella posibilita, cuando se publica en revistas de prestigio, necesariamente en inglés. La victoria obtenida por la publicación en estas revistas parece representar un lujo a que pocos tienen acceso. En este artículo se presenta una reflexión sobre las dinámicas que definen y controlan los contextos de la publicación y las definiciones de la ciencia, cuya publicación en portugués tiende a quedarse en un plan secundario o marginal. PALABRAS-CLAVE: Editoración; Comunicación; Información.

${ }^{1}$ Enfermeira. Doutora em Sociologia. Professora Coordenadora da Universidade de Évora. Pesquisadora do Instituto Universitário de Lisboa e do Centro de Investigação e Estudos de Sociologia - Lisboa-Portugal. 


\section{O Desafio de Publicar em Português}

Nos últimos anos, têm-se assistido a um aumento considerável quer das capacidades instaladas para a realização de investigação, quer da disputa por recursos para a pesquisa; assim como na redução de recursos públicos na maioria dos países. Um dos requisitos decisivos para ascender ao financiamento é a demonstração da produtividade dos grupos de pesquisa, sobretudo em termos de publicação nas revistas de melhor reputação nas respectivas áreas. Ora este processo não ocorre sem efeitos colaterais indesejados ${ }^{(1)}$.

A competição tende cada vez mais a transformarse numa luta renhida e desenfreada pela publicação, não apenas para se divulgar os resultados do trabalho científico produzido, mas também pela necessidade de se manter as esferas de prestígio e influência, notadamente no meio acadêmico. Este processo irreversível e incontrolável tem gerado inúmeros incidentes no meio universitário e não parece fácil de ser controlado.

Apesar da literatura científica e especializada estar mais acessível, é cada vez mais difícil ler o que é publicado nas correspondentes áreas de interesse. A atualização científica por parte do profissional, em cada área do conhecimento, tornou-se praticamente uma fantasia, impossível de se concretizar no cotidiano. Assim, existem e continuarão a existir muitos artigos que jamais serão lidos ou muito pouco lidos. Apesar das dificuldades e de se ter uma estimativa a esse respeito, há quem aponte como sendo de $50 \%$ o total de trabalhos publicados que jamais serão lidos ou citados ${ }^{(2)}$.

São múltiplos, críticos e até jocosos (produtividade crônica; publicacionismo agudo) os termos que começam a surgir para designar esta proliferação da literatura científica, inclusive muito questionada em termos éticos. Esta imperiosa necessidade de publicar, para responder às exigências que muitos consideram desajustadas e prejudiciais para a própria ciência, começa a ser questionada. Também o debate sobre se um artigo traz efetivas contribuições para o conhecimento, tem sido alvo de atenção especial. Esta, no entanto, parece ser uma questão de retórica, porque à suposta objetividade da ciência opõe-se a subjetividade dos revisores ${ }^{(2-3)}$.

A necessidade de produzir artigos que gerem citações é quotidiana. As pressões acerca do local de publicação e do seu impacto fazem com que uma das principais atividades dos investigadores seja a de gerar interesse em relação a seu objeto de estudo, nos diferentes níveis do processo de produção científica, e assim despertar o interesse de revistas científicas pelos seus artigos e linhas de pesquisa ${ }^{(4)}$.
A seletividade das revistas científicas é central para o investigador e é regida por critérios de oferta e procura. Por exemplo, o British Medical Journal informa os autores, que desejam a ele submeter os seus trabalhos, apenas $12 \%$ dos artigos submetidos anualmente, são aprovados ${ }^{(5)}$. Este número, revestidos do simbolismo próprio do prestígio que se quer defender e manter, é revelador da dura competição que impera no universo da publicação.

A dimensão mercadológica ligada à publicação científica também tem sido analisada e discutida, considerando-se que a autoria de artigos se tornou uma moeda corrente. O seu valor de troca já não é apenas simbólico, mas tem agregado prestígio e reconhecimento dos seus autores, permitindo-os manter-se ativos e influentes no território altamente competitivo que é a comunidade científica. Os investigadores precisam publicar, seja por razões normativas definidas pelos indispensáveis intercâmbios que definem o avanço da atividade científica, seja pela necessidade de se mostrar produtivos perante aqueles que financiam as suas pesquisas ou que julgam os seus currículos. Por isso, grande parte dos autores dedica-se a seguir a rotina de protocolos estabelecidos em propostas de investigação aceitas pelas agências financiadoras e consagradas pela comunidade científica, num trabalho burocrático, a perder de vista ${ }^{(2)}$.

Por sua vez, os líderes de grupos de pesquisa, para além de sua competência técnico-científica, passam a atuar cada vez mais como gestores de produtos, de recursos humanos, financeiros e de equipamentos. $\mathrm{O}$ objetivo final é manter ativas as fontes de financiamento para dar continuidade à sobrevivência de seu grupo, que é uma forma de manter a sua própria existência no campo $^{(3)}$. Em ambos os casos, é necessário, mais uma vez, ressaltar as dificuldades na aceitação de trabalhos em revistas mais prestigiadas, que publicam em inglês e que pertencem a contextos em que a produção científica é mais extensa (União Européia e Estados Unidos). Mas não se trata apenas da hegemonia do idioma; trata-se do domínio de temas e contextos mais valorizados e daqueles que são mais capazes de gerar interesse e de serem aceitos pelas revistas de maior prestígio.

Há também uma competição entre as próprias revistas que procuram manter o seu prestígio e que se traduz na capacidade de receber a chancela de indexadores consagrados (em geral, anglo-saxônicos, com destaque para o MEDLINE e o ISI), após duras provas para serem aceitas e preencher aos requisitos para se manter numa boa posição, controladas por instâncias especializadas na produção dos rankings bibliométricos. Nestes indexadores tem-se acesso, entre outros 
aspectos, aos artigos mais citados, da temporada, como se tratasse de moda ou do consumo de outros bens. Assim, tem-se informações dos êxitos e daqueles que estão in e out, em cada estação ${ }^{(6)}$.

O artigo científico é uma das principais formas de capital científico, com poder de gerar sempre mais capital. A comercialização da pesquisa científica manifestase pela progressiva mercadorização do artigo científico, pautada por negociações entre autores, editores, aspectos técnico-científicos da avaliação do artigo, limites éticos e concessões dos investigadores para publicar os seus artigos e para aceitar os dos outros ${ }^{(7)}$.

A preocupação com a detecção e o combate das práticas científicas que se desviam dos princípios éticos e o controle para regular o trabalho científico não parecem ser suficientes para lidar com os excessos do panorama atual. As próprias tentativas de controle correm o risco de se tornar também excessivas ${ }^{(2)}$.

Atendendo ao fato de que a necessidade de financiamento se torna progressivamente maior à medida que mais tecnologia é incorporada na ciência, obter verbas nos órgãos de fomento tornou-se a expressão máxima da competição entre os pesquisadores. Neste processo, a classificação do currículo do pesquisador, a partir de uma pontuação detalhada de cada atividade considerada relevante, é decisiva. Ora, nos últimos anos, nesta classificação, tem sido especialmente valorizada a publicação de artigos científicos em revistas de grande impacto. Os artigos publicados podem variar numa escala de pontuação que vai do máximo, que são os artigos completos em periódicos internacionais indexados e de grande impacto na comunidade científica (em função do número de consultas e citações), até ao mínimo, que são os artigos resumidos em periódicos (nacionais ou regionais) de baixo impacto ${ }^{(4)}$.

Mas, para publicar em revistas de grande impacto, impõe-se que se domine a língua inglesa. No sistema de classificação atual, a principal qualidade de um investigador é sua capacidade de publicar artigos em inglês. Segundo as atuais normas de pontuação, um artigo publicado em inglês é melhor do que qualquer outro publicado em português, ou em qualquer outra língua.

No entanto, há quem não concorde que publicar em inglês deva ser a prioridade e aqui se encontra o grande divisor entre os pesquisadores. De um lado, há aqueles que defendem que a ciência é universal e que os temas mais avançados do conhecimento internacional são aqueles que, de fato, interessam, não existindo ciência nacional ou regional, decorrendo daí a necessidade de se publicar predominantemente em inglês e dialogar com a comunidade internacional. Estes sustentam, ainda, que se deveria estimular a publicação em inglês porque, mesmo as revistas mais respeitadas em países desenvolvidos como Alemanha, Japão, Espanha, França e Portugal, já estão a capitular na sua resistência linguística, passando a publicar em inglês. Pesquisadores deste grupo argumentam, também, que mesmo aqueles que publicam em português, em $86 \%$ das vezes, utilizam como fonte de consulta a literatura internacional em inglês nas revistas da sua área e que a suposta credibilidade do artigo lhe é conferida, precisamente, pelas referências em inglês ${ }^{(8)}$.

Finalmente, este grupo considera que a feroz competição pela publicação seria um mecanismo saudável de seleção e que a sobrevivência neste processo é indispensável para caracterizar a chamada "boa ciência". Então, o diálogo entre cientistas passa necessariamente pela leitura e escrita em inglês. Mas, há também quem duvide que esta competição seja saudável, uma vez que a pressão para obter resultados positivos, que agradem aos financiadores, pode gerar conclusões intencionalmente falsas e interpretações distorcidas face às pressões do mercado ${ }^{(9)}$.

Atendendo ao crescimento da produção científica brasileira, muitos defendem que se deveria dialogar em português com a comunidade a que se pertence, pelo menos com a mesma frequência com que se faz em inglês. Nesta comunidade, a produção brasileira seria hegemônica e ditaria muitas das agendas científicas, sem ter que se ajustar aos temas e problemas propostos pela comunidade científica internacional ${ }^{(3)}$. Neste grupo, defende-se que não há ciência universal, mas sim uma distribuição desigual do conhecimento em função das disparidades históricas e sociais entre as diferentes comunidades científicas nas suas origens. Seus membros salientam, ainda, que as ditas publicações internacionais raramente são, de fato, internacionais no seu conteúdo, nos seus leitores e no seu corpo editorial, apresentandose antes como expressões evidentes dos interesses próprios da comunidade de língua inglesa, as quais poderão liquidar de vez as publicações nacionais e regionais, dificultando ainda mais o acesso dos investigadores à difusão do conhecimento contemporâneo (nos países que não adotam o inglês como língua oficial) ${ }^{(10)}$.

$\mathrm{O}$ fenômeno tratado neste artigo parece encontrar um total eco com os sistemas de pontuação das instâncias de fomento da ciência em países como Portugal e Brasil, gerando uma situação nociva para a ciência feita e falada em português. Se os artigos em português fossem valorizados, haveria artigos de maior qualidade e a quantidade 
de energia investida para se poder dialogar com as revistas internacionais - e, simultaneamente, para se poder dedicar às publicações nacionais - seria bem diferente.

Apesar da época em que a publicação nos periódicos brasileiros ou portugueses era vista com um certo demérito já ter passado, publicar em língua portuguesa ainda continua a ser uma segunda escolha, mesmo quando se verifica que, nos últimos nove anos, os downloads de manuscritos da colecção SciELO (Scientific Electronic Library Online) passaram de menos meio milhão para quase 100 milhões de acessos por ano ${ }^{(11)}$. Os trabalhos publicados em periódicos de língua inglesa, com alto fator de impacto, não são necessariamente sinônimo de trabalho de qualidade indiscutível, assim como não se pode generalizar que artigos publicados em periódicos de língua portuguesa sejam de baixa qualidade. Apesar do domínio hegemônico da língua inglesa, não se pode dizer que a distorção do sistema de avaliação da produção científica seja um problema exclusivo do Brasil ou de Portugal, uma vez que a insatisfação com os critérios de atribuição de verbas para a pesquisa é geral, pois como se viu, ele tem a ver com a dinâmica mercantil. Também a desonestidade científica, que cresceu tanto nos últimos anos, é geral e afeta a credibilidade de muitas revistas e do sistema de revisão realizado pelos consultores $a d$ hocs. Mesmo revistas de alta posição como a Science ou a Nature não escapam à humilhação de verem publicados resultados de pesquisa fraudulentos, o que revela que não há sistemas, nem revistas perfeitas, por mais prestígio que tenham e por mais pontos que rendam a quem nelas publica, em inglês.

A publicação noutro idioma, que não o próprio, apresenta dificuldades que, na maioria das vezes, estão associadas à escrita/tradução. Os cursos de escrita científica em inglês podem ajudar os investigadores a adquirir as habilidades e competências necessárias. Desta forma, o próprio investigador escreve o seu artigo em inglês, adequando a linguagem e os termos, sem a intermediação dos tradutores, que por mais habilitados que sejam, não detêm os conhecimentos e as articulações próprias de qualquer área científica.

Sobre as dificuldades na aceitação do português como língua de publicação internacional, lembra-se que a língua portuguesa é falada por 218 milhões de pessoas e que é o sétimo idioma mais falado no mundo. Se o português se juntar ao quarto idioma (o espanhol com 425 milhões de falantes), ficar-se-ia com 643 milhões de indivíduos, o que então constitui a segunda maior comunidade linguística mundial. As similaridades, a proximidade e a relação de vizinhança, fruto da inserção geográfica, reforçam esta ideia, de uma grande comunidade com duas línguas que todos compreendem e que se afirme como promotora do desenvolvimento científico. Este é um desafio que merece a atenção e que deve começar a ser discutido.

\section{REFERÊNCIAS}

1. Newman F, Couturier L, Scurry J. The future of higher education: rhetoric, reality, and the risks of the market. San Francisco: Jossey-Bass; 2004.

2. Castiel LD, Sanz-valero J, Cyted RM. Entre fetichismo e sobrevivência: o artigo científico é uma mercadoria acadêmica? Cad Saúde Pública. 2007;23(12):3041-50.

3. Rodrigues LOC. Publicar mais, ou melhor? O tamanduá olímpico. Rev Bras Ciênc Esporte. 2007;29(1):35-48.

4. Pessanha C. Critérios editoriais de avaliação científica: notas para discussão. Perspect Ciênc Inf. 1998;27(2):226-9.

5. BMJ. Instructions for authors. [Internet]. [acesso em 12 out 2010]. Disponível: http://bmj.bmjjournals.com/ advice

6. Wills M, Wills G. The ins and the outs of electronic publishing. Internet Res. 1996;6(1):10-21.

7. McSherry C. Who owns academic work? Battling for control of intellectual property. Cambridge: Harvard University Press; 2001.

8. Melo JRC, Santos GC, Andrade MV. Brazilian medical publications: citation patterns for Brazilian-edited and non-Brazilian literature. Braz J Med Biol Res. 2006;39:997-1002.

9. Ioannidis JPA. Why most published research findings are false. PloS Medicine. 2005;2(8):696-701.

10. Ofori-Adjei D, Antes G, Tharyan P, Slade E, Tamber PS. Have online international medical journals made local journals obsolete? PloS Medicine. 2006;3(8):1197-201.

11. Silva RM. O novo qualis, que não tem nada a ver com a ciência do Brasil. Carta aberta ao presidente da CAPES. Clinics. 2009;64(8):1-4. 